\title{
EFEITO DO ENXOFRE NA PRODUÇÃO DA SOJA $\left({ }^{1}\right)$.
} Rúter Hiroce e J. Romano Gallo $\left(^{2}\right)$. Respostas ao enxofre têm sido observadas, no Estado de São Paulo, em culturas de café, milho, algodão, feijão, amendoim e soja, principalmente em solos de vegetação de cerrado, mediante adição de gesso (sulfato de cálcio) na adubação normal. $O$ enxofre é também adicionado ao solo através de adubos que, embora não sendo especificamente sulfatados, contenham esse elemento. Tal fato pôde ser constatado no presente trabalho.

No ano agrícola de 1965/1966 foi instalado um ensaio de doses crescentes de calcário, cloreto de potássio e superfosfato simples, em cultura de soja (Glycine max (L.) Merril), em Latossolo Roxo com vegetação de cerrado, no município de Ipuã, SP $\left({ }^{3}\right)$. Na época do florescimento, de 20 plantas, aproximadamente, foram coletadas amostras das terceiras folhas, a partir do ápice da haste principal.

Nessas amostras, secas em estufa, à temperatura de $60-70^{\circ} \mathrm{C}$, foram determinados os elementos nitrogênio, fósforo, potássio, cálcio, magnésio e enxofre.

Os resultados das análises químicas revelaram aumento estatisticamente significativo do teor de enxofre nas folhas, em função das doses crescentes de superfosfato simples, em concordância com o aumento da produção. Não houve, entretanto, aumento de fósforo ou de cálcio, elementos também constituintes desse adubo, possivelmente pela suficiência desses nutrientes no solo, a julgar, ainda, pelos resultados das análises das folhas (quadro 1). Não se observaram efeitos do calcário ou do cloreto de potássio.

Próximo do local desse ensaio, em experimento que recebeu superfosfato triplo, superfosfato triplo mais gesso e superfosfato simples, somente não houve aumento de produção, em relação à testemunha, para o tratamento com superfosfato triplo $\left(^{4}\right)$.

\footnotetext{
(1) Trabalho apresentado na XXII Reunião Anual da Sociedade Brasileira para o Progresso da Ciência, realizada em Salvador, Bahia, de 5 a 11 de julho de 1970. Recebido para publicação em 27 de setembro de 1971.

(?) Com bolsa de suplementação do $\mathrm{CNPq}$.

$\left(^{3}\right)$ MASCARENHAS, H. A. A.; MIYASAKA, S.; IGUE, T. \& FREIRE, E. S. Adubação da Soju. VII - Efeito de doses crescentes de calcário, fósforo e potássio em solo Latossolo Roxo com vegetação de cerrado recém-desbravado. Bragantia 27:279-289, 1968.
} 
Quadro 1. - Teores médios de nitrogênio, fósforo, potássio, cálcio, magnésio e enxofre, nas folhas de soja, e produções médias, em' função das doses de superfosfato simples aplicadas no solo

\begin{tabular}{|c|c|c|c|c|c|c|c|}
\hline \multirow{2}{*}{$\begin{array}{l}\text { Dose de } \\
\text { super- } \\
\text { fosfato } \\
\text { simples }\end{array}$} & \multicolumn{6}{|c|}{ Teor médio do elemento na matéria seca $\left(^{*}\right)$} & \multirow{2}{*}{$\begin{array}{l}\text { Produ- } \\
\text { ção }\end{array}$} \\
\hline & $\mathbf{N}$ & $P$ & $\mathbf{K}$ & $\mathrm{Ca}$ & $\mathrm{Mg}$ & $\mathrm{S}_{-} \mathrm{SO}_{4}$ & \\
\hline $\mathrm{kg} / \mathrm{ha}$ & $\%$ & $\%$ & $\%$ & $\%$ & $\%$ & $p p m$ & $k g / h a$ \\
\hline $0 \ldots \ldots$ & 3,48 & 0,316 & 2,71 & 1,04 & 0,48 & $545 \mathrm{a}$ & $1734 \mathrm{a}$ \\
\hline $500 \ldots \ldots$ & 3,63 & 0,316 & 2,74 & 1,00 & 0,47 & $626 \mathrm{ab}$ & $2580 \mathrm{~b}$ \\
\hline $1000 \ldots$. & 3,72 & 0,314 & 2,74 & 0,97 & 0,49 & $790 \mathrm{~b}$ & $2634 \mathrm{~b}$ \\
\hline
\end{tabular}

(*) Letras comuns entre as médias indicam diferenças não significativas, e as não comuns, diferenças significativas, pelo teste de Tukey a $5 \%$.

Esses resultados vieram confirmar que o superfosfato simples pode atender às necessidades de enxofre, em solos carentes desse elemento. SEÇÃO DE QUIMICA ANALÍTICA, INSTITUTO AGRONOMMICO DO ESTADO DE SÃO PAULO.

\section{EFFECT OF SULPHUR ON SOYBEAN (GLYCINE MAX (L.) MERRIL) PRODUCTION}

\section{SUMMARY}

Several cultures, such as coffee, cotton, corn, peanut, dry bean and soybean, have been observed to respond positively to sulphur applied under the form of gypsum $\left(\mathrm{Ca} \mathrm{SO}_{4}\right)$, in the State of São Paulo. On the other hand, it is known that sulphur is also added to the soil as a normal component of some fertilizers (e.g. superphosphate). The effect of such an "indirect" sulphur fertilization on the sulphur content of soybean leaves was studied.

Foliar analyses indicated that increasing dosis of single superphosphate resulted in increasing content of sulphur, in soybean leaves. There was no increase in phosphorus or calcium, the other components of this ferlilizer, in the same leaves, possibly because the soil was well supplied for both elements. The results show that single superphosphate might be a source for sulphur fertilization.

( ${ }^{4}$ ) MASCARENHAS, H. A. A.; MIYASAKA, S.; FREIRE, E. S. \& IGUE, T. Adubação da soja. VI - Efeitos do enxôfre e de vários micronutrientes ( $\mathrm{Zn}, \mathrm{B}, \mathrm{Mn}, \mathrm{Fe}$ e $\mathrm{Mo}$ ), em Latosol roxo com vegetação de cerrado. Bragantia 26:373-379, 1967. 